\title{
МЕХАНИЗМЫ ВЫЖИГАНИЯ ПРОВАЛОВ В СПЕКТРАХ ХЛОРОФИЛЛА И ФЕОФИТИНА
}

\section{Введение}

Применение селективного лазерного возбуждения позволило значительно продвинуться вперед в изучении тонкоструктурных вибронных спектров хлорофиллоподобных молекул [ $\left.{ }^{1}\right]$. Все же спектральное разрешение, определяемое неоднородной шириной колебательных подуровней, оставалось в пределах 5-10 $\mathrm{cm}^{-1}$ : Для измерения резонансных чисто электронных линий (ЧЭЛ), которые могут иметь однородную ширину меньше $10^{-3} \mathrm{Cm}^{-1}$, А. А. Гороховским и др. $\left.{ }^{2}\right]$ был предложен метод фотохимического выжигания провала: молекулы, поглощающие монохроматический свет через их ЧЭЛ, с некоторой вероятностью покидают свои места в неоднородном контуре, где образуется узкий провал.

Наиболее ясен механизм возникновения т. н. фотофизического провала, который образуется в результате заселения долгоживущего триплетного состояния. Исследование такого типа провалов встречает, однако, специфическую трудность - измерение нужно успеть провести до опустошения триплета, которое в случае хлорофилла $a$ (Хл $a$ ) длится всего несколько миллисекунд. Џспользуя регистрацию с временным окном, нам удалось зафиксировать провал триплетного происхождения в спектре поглощения Хл $a\left[{ }^{3}\right]$. Однако из-за нерезонансного возбуждения он был широк и невыразителен, отчего фотохимические лроцессы, намеки на которые были отмечены, с трудом поддавались изучению. Позже Р. М. Шелби и Р. М. Макфэрлейн [ $\left.{ }^{4}\right]$, используя сканируемый одночастотный лазер, измерили узкий $\left(0,005 \mathrm{~cm}^{-1}\right)$ резонансный провал насыщения триплетного резервуара в спектре возбуждения $\mathrm{Zn}$-порфина.

Недавно на усовершенствованной аппаратуре мы детально исследовали процессы выжигания провала в спектрах протохлорофилла (ПХл), Хл $a$ и других близких по строению соединений $\left[{ }^{5,6}\right]$. Новые данные подтверждают существенную роль фотофизического механизма и, кроме того, точно указывают на сосуществующий фотохимический механизм. На основе фотообратимости процесса и его кинетических свойств сделан вывод, что этот механизм заключается во взаимопревращении примесных молекул в пределах контура функции неоднородного распределения (ФНР). Такие взаимопревращения предложены Б. М. Харламовым и др. $\left[{ }^{7}\right]$ в качестве одного из основных механизмов выжигания и в последнее время детально обсуждались Дж. М. Хейэсом и Дж. Дж. Смолом $\left[{ }^{8}\right]$, которые выдвигали различные гипотезы о путях взаимопревращений в стеклообразных матрицах. То, что метод выжигания провала позволяет изучать некие общие свойства стекол, подчеркнуто также в [ $\left.{ }^{9}\right]$. В случае хлорофилла более важной является аналогия с конфигурационными изменениями в первичной стадии фотосинтеза.

Совершенно иной механизм выжигания - таутомерный поворот центральных протонов - установлен в случае безметального хлорофилла - феофитина (Фф) $\left[{ }^{10}\right]$. Существование этого механизма напра- 

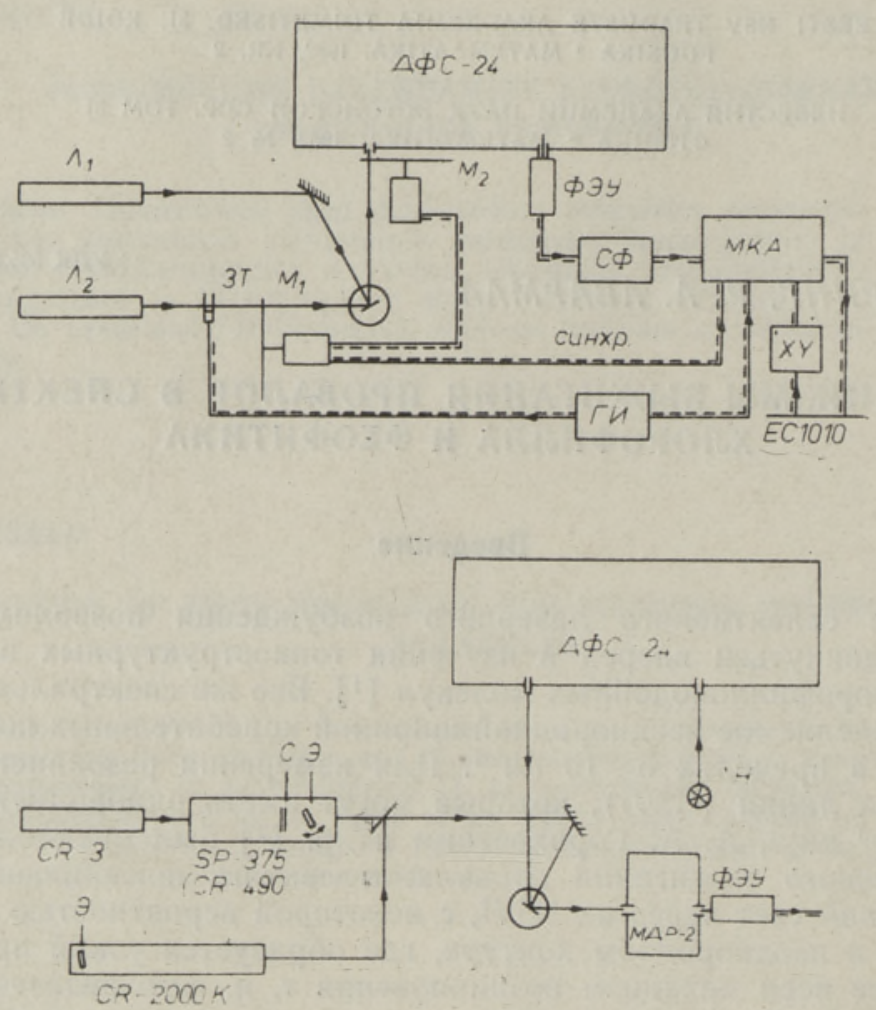

Рис. 1. Установки для измерения провалов в спектрах флуоресценции (вверху) и возбуждения (внизу): $Л_{1}, Л_{2}$ - лазеры, $M_{1}, M_{2}$ - модуляторы фосфороскопа, ЗТ - затвор, СФ - система счета фотонов, МКА - многоканальный анализатор, ГИ - генератор импульсов, ЛН - лампа накаливания, С - селектор длнны волны, Э - эталон.

шивалось по аналогии с фталоцианином $\left[{ }^{2}\right]$, порфином $\left[{ }^{11}\right]$ и хлорином $\left[{ }^{12}\right]$, однако его обнаружение оказалось нетривиальным. В то время как указанные молекулы в $н$-алканах обладают четкими линейчатыми спектрами, полосы Фф а неоднородно уширены. У порфина таутомерный поворот вызывает незначительный сдвиг ЧЭЛ [ $\left.{ }^{11}\right]$, у хлорина, из-за более низкой симметрии, два таутомера неэквивалентны и сдвиг составляет $1500 \mathrm{~cm}^{-1}\left[{ }^{12}\right]$. У Фф $а$ наряду с основной полосой при 670 нм была обнаружена полоса флуоресценции фотопродукта 650 нм, т. е. таутомерный сдвиг равен $\approx 500 \mathrm{~cm}^{-1}$. Дополнительные измерения спектра возбуждения, квазилинейчатой структуры, вторичного провалообразования и кинетики превращений подтвердили гипотезу о таутомерном механизме выжигания. Отметим, что таким образом было наблюдено фотохимическое образование ранее неизвестной формы безметального хлорофилла.

Обзор этих исследований был представлен на X Международной конференции по фотохимии $\left[{ }^{13}\right]$. Здесь мы затрагиваем лишь два малоизученных аспекта проблемы: во-первых, вид фононных крыльев, которые важны потому, что могут дать основной вклад в формирование однородных спектров хлорофилла при промежуточных температурах $(\sim 100 \mathrm{~K})$, и, во-вторых, возможность использования однородных ширин вибронных уровней для оценки скорости колебательной релаксации. 


\section{Методика эксперимента}

Использовали два варианта эксперимента (установки см. на рис. 1). В первом из них, приспособленном для измерения резонансных провалов в спектре флуоресценции, применялось двухлучевое возбуждение: выжигание лазером $\Omega_{1}$ и неселективное возбуждение флуоресценции пробным лучом от лазера $\boldsymbol{Л}_{2}$. Рассеянный свет выжигающего луча отсекался двухдисковым сельсинным фосфороскопом. Для изучения медленной кинетики служил дополнительный затвор. Во втором варианте провал сначала выжигался на постоянной длине волны, а затем измерялся спектр возбуждения флуоресценции около линии выжигания. Для измерения узких провалов в лазер на красителе дополнительно устанавливался эталон Фабри-Перо, медленно поворачиваемый вокруг своей оси. Наивысшее разрешение обеспечивал криптоновый лазер, работающий в одномодовом режиме, причем сканирование по точкам осуществлялось поворотом внутрирезонаторного эталона (ннтервал между модами $\left.3 \cdot 10^{-3} \mathrm{CM}^{-1}\right)$.

Система регистрации была одинаковой в обоих случаях. Многоканальный анализатор имел двухсторонний канал обмена информации с ЭВМ ЕС 1010. Для определения параметров провалов использовались специальные программы обработки данных.

\section{Результаты и обсуждение}

В спектре флуоресценции ПХл отчетливо наблюдается провал, возникший в результате заселения низшего триплетного состояния. На рис. 2 изображена часть спектра флуоресценции ПХл с резонансным провалом, затухающим во время опустошения $T_{1}$-состояния (среднее время жизни $\tau_{T}=9$ мс $\left.\left[{ }^{14}\right]\right)$. Разностный спектр (рис. 2, 3) т. н. спектр выжигания $\left[{ }^{15}\right]-$ состоит из узкой ЧЭЛ и широкого фононного крыла. Ширина линии $0,5 \mathrm{~cm}^{-1}$ в данном случае определяется аппаратной функцией.

Обращает на себя внимание четкость фононного крыла. Как показано в $\left[{ }^{16}\right]$, спектр выжигания содержит те же три компоненты фононного крыла, что и монохроматически возбуждаемый спектр флуоресценции $\left[{ }^{17}\right]$. В итоге кажущийся фактор Дебая-Валлера (относительная

Рис. 2. Резонансный провал и его фононное крыло в спектре флуоресценции протохлорофилла в смеси эфир-бутанол при $T=5 \mathrm{~K}$. Спектры измерены по схеме бокскара без задержки $(I)$ и с задержкой 15 мс (2) после выжигания, разность спектров 2 и 1 в увеличенном масштабе (3).

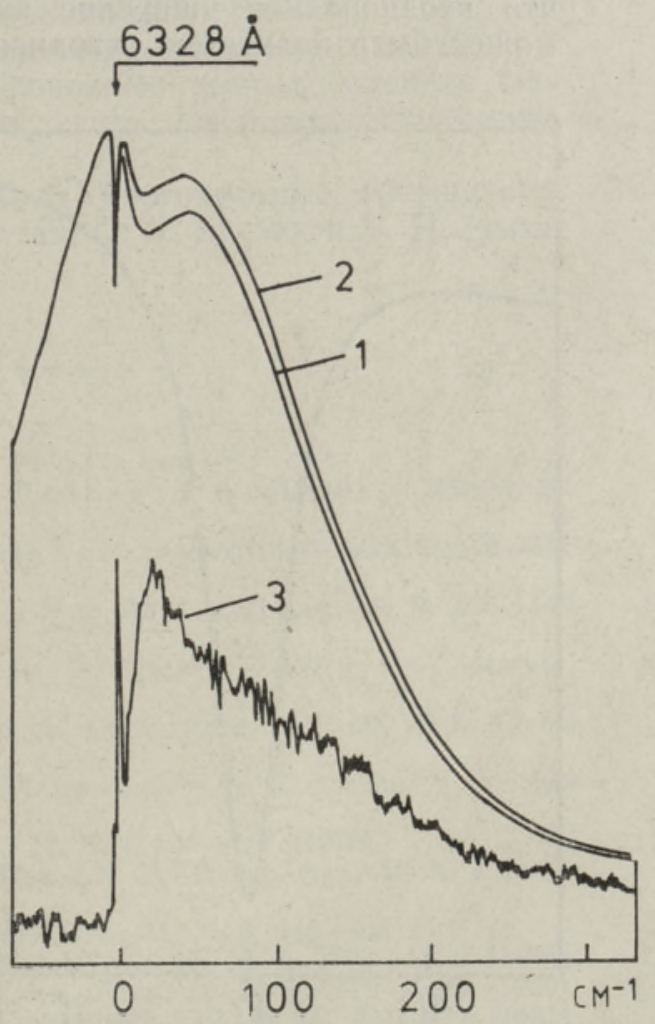


интегральная интенсивность ЧЭЛ) в обоих случаях приблизительно равен квадрату его однородного значения $\alpha$. На основе спектра выжигания на рис. 2 получили $\alpha \simeq 0,15$. Это значение позволяет говорить об умеренном электрон-фононном взаимодействии в данной системе. Аналогичный результат был получен для ПХл в $н$-гептане.

Следует отметить, что измерение именно спектра выжигания чисто триплетного происхождения дает достоверный вид фононного крыла. Если, например, из первоначального спектра вычесть спектр после выжигания, то разность будет отражать и результат перераспределения ФНР. Те перескоки, которые не выходят за пределы фононного крыла, участвуют лишь в образовании узкого провала, а ощутимого вклада в наблюдаемое крыло не дают. Поэтому интенсивность крыла получается заниженной, что подтверждают эксперименты по кинетическим измерениям в области фононного крыла $\left[{ }^{6}\right]$.

В случае Хл $a$ из-за более короткого времени жизни триплета фотофизический механизм давал меньший вклад в выжигание, чем перераспределение центров. Поскольку последний процесс сравнительно замедлен и необратим в темноте, то использовали в основном вторую схему эксперимента. В спектре возбуждения Хл $a$ при $1,8 \mathrm{~K}$ провал получился шириной $0,01 \mathrm{~cm}^{-1}$ - рекордной для хлорофилловых молекул. Так как это значение находится на пределе разрешения нашей аппаратуры, можно указать лишь верхний предел однородной ширины ЧЭЛ $\Gamma_{00} \leqslant 0,005 \mathrm{~cm}^{-1}$. Нижний предел, определяемый распадным уширением $S_{1}$-состояния Хл $a\left(\tau_{1}=8 \mathrm{Hc}\right)$, меньше еще на порядок.

Узкая ЧЭЛ позволяет считать модуляционное уширение пренебрежимо малым для возбужденных колебательных уровней. Поэтому их однородные ширины можно использовать для оценки скоростей релаксации. Для этого мы выжигали провалы в области вибронных переходов спектра возбуждения. При этом подтвердился вывод $\left[{ }^{18}\right]$ о том, что неоднородное уширение вибронных подуровней $S_{1}$-состояния не может быть полностью устранено селекцией $0-0$-энергии. В то время

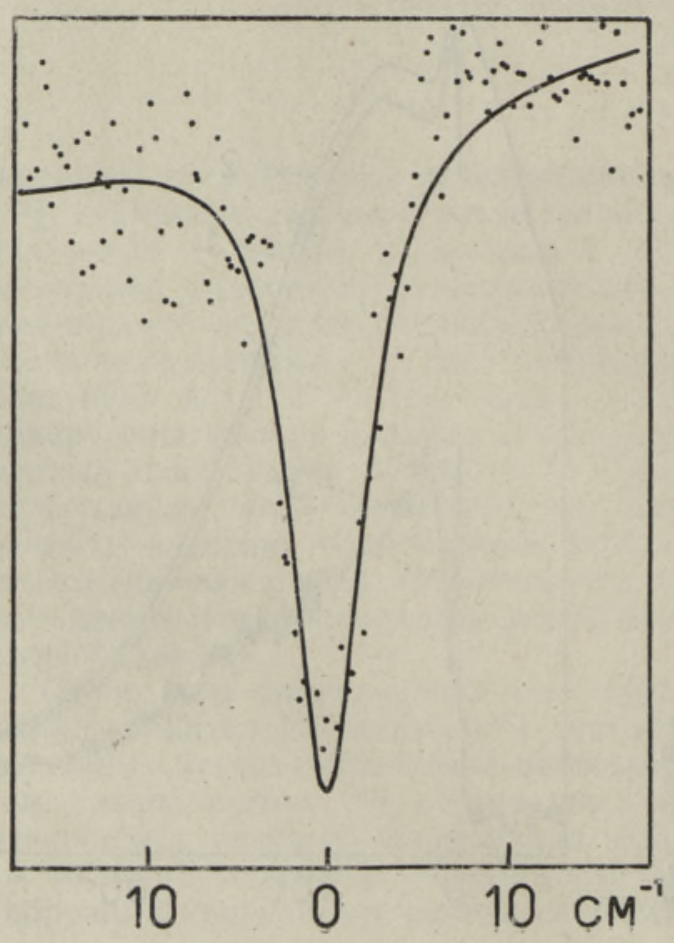
как ширина линии спектра возбуждения Хл $a$ при монохроматической регистрации флуоресценции была 5-10 $\mathrm{cm}^{-1}$, peзонансные провалы оказались шириной $1-3 \quad \mathrm{~cm}^{-1}$. Контур провала определялся по разности спектров возбуждения с узкополосной регистрацией до и после выжигания, т. е. прөвал выжигался в отдельных квазилиниях спектра возбуждения. Такая методика, ставшая возможной благодаря специальным программам .обработки данных на ЭВМ, позволяла мерить однородные ширины отдельных колебательных подуровней (рис. 3). Провалы

Рнс. 3. Провал в вибронной линии $1240 \mathrm{~cm} \mathrm{n}^{-1}$ спектра возбуждения Хл $a$ в эфире при $T=4,2 \mathrm{~K}$. Аппроксимация лоренцевой кривой шириной $\Gamma=4,2 \mathrm{CM}^{-1}$, 
хорошо аппроксимировались лоренцевыми кривыми; в этом случае однородная ширина линии равна половине наблюдаемой $\left[{ }^{17}\right]$. Были получены значения $\Gamma=1,3,2,5$ и $2,1 \mathrm{~cm}^{-1}$, соответственно, для колебаний 740,980 и $1250 \mathrm{~cm}^{-1}$ в возбужденном электронном состоянии. Соотношение неопределенности дает для соответствующих времен жизни $\tau_{r}$ колебательных состояний оценки $4,0,2,1$ и 2,6 nc.

Аналогичным способом исследовались времена колебательной релаксации молекулы порфина в $\boldsymbol{H}$-октане $\left[{ }^{19}\right]$. Для большинства уровней получились времена жизни в несколько пикосекунд, за исключением двух колебаний, имевших по $\tau_{r}=40$ nc. В случае Хл $a$ наличие медленно релаксирующих колебаний менее вероятно из-за бо́льшей плотности колебательных состояний (это требует дальнейшей проверки).

Эффективным способом определения скоростей релаксации является измерение горячей люминесценции $\left[{ }^{20}\right]$, если она достаточно интенсивна. Полученные нами значения $\tau_{r}$ позволяют оценить, что интенсивность горячей люминесцении Хл $a$ может составлять $10^{-4}$ от обычной флуоресценции. Это согласуется с выводами прямых измерений $\left[{ }^{21}\right]$, согласно которым наблюдению горячих полос мешают посторонние Хл $a$ примеси в количестве $10^{-3}$.

\section{Заключение}

Для хлорофиллоподобных молекул в замороженных растворах установлены три механизма выжигания провалов: 1) накопление молекул в триплетном состоянии, 2) их взаимопревращение в пределах ФНР, 3) таутомерное вращение центральных протонов в безметальных соединениях. Первый из них (фотофизический) обратим спонтанно, остальные два - за счет светового или теплового возбуждения. Имеются также сведения о выжигании провала в хлоропластах $\left[{ }^{22}\right]$, где в игру вступают фотохимические процессы реакционных центров.

Провалообразование наряду с повышением эффективного спектрального разрешения позволило изучить фононные крылья, оценить скорость колебательной релаксации и проследить некоторые фотохимические превращения.

Авторы благодарны К. К. Ребане за многократные обсуждения, А. П. Суйсалу за участие в экспериментах, С. А. Куузик и В. И. Нымм за приготовление препаратов.

\section{ЛИТЕ Р А Т Р А}

1. А в а р м а а Р. А. (см. настоящий номер)..

Re b a ne, K. K., Avarma a, R. A., Chem. Phys. (в печати).

2. Гороховский А. А., Ка арли Р. К., Ребане Л. А., Письма в ЖЭТФ, 20, выг. 7, 474-479 (1974).

3. А в а р м а а Р. А., М а ур н н г К. Х., Оптика и спектроскопия, 41, вып. 4, 670-671 (1976).

4. Shelby, R. M., Macfarlane, R. M., Chem. Phys. Lett., 64, № 3, 545-549 (1979).

5. Мауринг К., Суйсалу А., Ав а м а а Р., Изв. АН ЭССР, Физ. Матем., 29, № $4,426-428$ (1980).

6. Avarma a, R., Ma uring, K., S u is a 1 u, A., Chem. Phys. Lett., 77, № 1, 88-92 (1981).

7. Х ар ламов Б. М., Персонов Р. И., Быковская Л. А., Оптика и спектроскопия, 39, вып. 2, 240-247 (1975).

8. H a y e s, J. M., S m a 11, G. J., Chem. Phys., 27, № 1, 151-157 (1978).

9. Гороховский А. А., Ре бан е Л. А., Изв. АН СССР, сер. физ., 44, № 4, 859 $862(1980)$.

10. Mauring, K., Avarma a, R., Chem. Phys. Lett., 81, № 3, 446-449 (1981).

11. Voelker, S., van der Wa als. J. H., Mol. Phvs., 32, № 6, 1703-1718 (1976).

12. Voelker, S., M a c f a r la ne, R. M., J. Chem. Phys., 73, № 9, 4476-4482 (1980).

13. Rebane, K. K., Avarmaa, R. A., J. Phoțochem., 17, № $3 / 4,311-317$ (1981). 
14. A v a rm a a, R., Mol. Phys., 37, № 2, 441-454 (1979).

15. Харламов Б. М., Быковска я Л. А., Персонов Р. И., Ж. прикладной спектроскопии, 28, вып. 5, 839-844 (1978).

16. Ки к а с Я. В., Автореф. канд. дис., Тарту, 1979.

17. А в а р м а а Р., Изв. АН ЭССР, Физ. Матем., 23, № 3, 238-247 (1974).

18. Gorokhovski, A. A., Kikas, J., Opt. Commun., 21, № 2, 272-274 (1977).

19. Voelker, S., M a c f a r l a ne, R. M., Chem. Phys. Lett., 61, № 3, 421-245 (1979).

20. Р е б ан е К. К., С а а ри П. М., Изв. АН СССР, сер. физ., 40, № 9, 1778-1784 (1976).

21. А в а рм а а Р. А., Т а мки в и Р. П., Ж. прикладной спектроскопии, 27, вып. 2, 259-262 (1977)

22. Маслов В. Г., Чунаев А. С., Тугаринов В. В., Биофизика, 25 , вып. 5 , 925-927 (1980).

Институт физики

Академии наук Эстьнской ССР

K. H. MAURING, R. A. AVARMAA

\section{AUGU MOODUSTUMISE MEHHANISMID KLOROFULLI JA FEOFOTIINI SPEKTRITES}

Klorofülli ja selle derivaatide spektrites leiti kolm erinevat augupõletuse mehhanismi: lisanditsentrite erinevate konfiguratsioonide muundumine üksteiseks, üleminek triplettolekusse ning tsentraalsete prootonite pööre. Mõõdeti ka foonontiibade kuju ja anti hinnang võnkerelaksatsiooni kiirusele.

K. H. MAURING, R. A. AVARMAA

\section{MECHANISMS OF HOLE-BURNING IN THE SPECTRA OF CHLOROPHYLL AND PHEOPHYTIN}

Three kinds of hole-burning mechanisms in the fluorescence and excitation spectra of chlorophyll $a$ and its closest derivatives are found: (1) transfer of population to the triplet state, (2) site interconversions within the inhomogeneous band, (3) tautomeric rotation of the protons in the centre of molecule. The hole-burning method is used for measuring the phonon wings and for estimation of the vibrational relaxation rates. 